\title{
Gallbladder Volvulus: A Case Study and Review of Literature
}

\section{Abstract}

Gallbladder volvulus or gall bladder torsion (GBT) is a relatively rare condition affecting roughly 1 in 365,520 patients. Only about 300 such cases have been reported in the literature but the age range is 2 to 100 years old. The first case was described by Wendel in 1898 in which he described it as a "floating gallbladder." It is defined as a rotation where there is a mechanical organo-axial torsion that occurs along the gallbladders longitudinal axis involving the cystic duct and artery. But the etiology is still not well known. The condition is overwhelming found in the geriatric population with $85 \%$ of patients being over the age of 60 . There is a predilection for white females as well.

Keywords: Gallbladder volvulus; Gallbladder torsion; Acute cholecystitis; Floating gallbladder; Chronic cholecystitis; Biliary peritonitis; Laparoscopic cholecystectomy

Received: May 13, 2017; Accepted: May 23, 2017; Published: May 30, 2017

\section{Introduction}

Definitive preoperative diagnosis is difficult as it is often confused for acute cholecystitis. Gallbladder volvulus can lead to obstruction of biliary drainage and arterial flow leading to ischemia, necrosis, perforation and biliary peritonitis. However, with timely diagnosis and surgical intervention of these complications can be prevented. Currently the disease mortality is quite low at roughly $5 \%$

\section{Case Presentation}

A 76 year old white female presented with severe right upper quadrant pain, nausea and emesis. The pain was described as achy and radiated to the right mid back. The patient's past medical history included hypertension, hyperlipidemia, gerd and irritable bowel syndrome. Her surgical history included a hysterectomy with bilateral salpingo ophrectomy and repair of an enterocele. On examination, the patient was tender in the right upper quadrant without guarding or rebound. Laboratory values and vital signs showed the following:

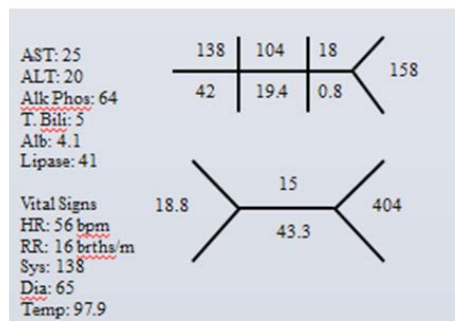

\section{Aaron Hayson', Justin Lee and}

\section{Alexander \\ RamirezValderama}

\author{
General Surgery Residency at Florida \\ State University College of Medicine and \\ Tallahassee Memorial Healthcare
}

Corresponding author: Aaron Hayson

\section{” awh2830@gmail.com}

General Surgery Residency at Florida State University College of Medicine and Tallahassee Memorial Healthcare.

Tel: $+850-431-5567$

\author{
Citation: Hayson A, Lee J, \\ RamirezValderama A. Gallbladder Volvulus: \\ A Case Study and Review of Literature. J \\ Univer Surg. 2017, 5:3.
}

A significant WBC of 18.8 was noted however the patient was afebrile. An Ultrasound was performed which showed no evidence of cholelithiasis (Figure 1) [1]. Biliary "sludge" was noted without cholecystic fluid or gallbladder wall thickening. Ultrasound impression was no acute process. A CT of the abdomen and pelvis was obtained. This showed a moderately distended gallbladder with pericholecystic fluid consistent with inflammation (Figures 2 and 3).

The patient was consented for a laparoscopic cholecystectomy with intraoperative cholangiogram; possible open cholecystectomy. Intraoperatively, a floppy/floating gallbladder was noted without attachment to the liver with the exception of the cystic artery and cystic duct. The gallbladder was rotated about its longitudinal axis in a counter clockwise fashion. The gallbladder appeared necrotic (Figures 4 and 5).

A cholecystectomy was performed in the routine fashion. Histological examination revealed a red-purple trabeculated mucosa. The serosa was hyperemic. The wall of the gallbladder measured to $0.5 \mathrm{~cm}$ thick. There were no stones within in the specimen. The gallbladder wall had extensive hemorrhage and necrosis consistent with torsion. The patient did well post operatively and was discharged to home the following day 


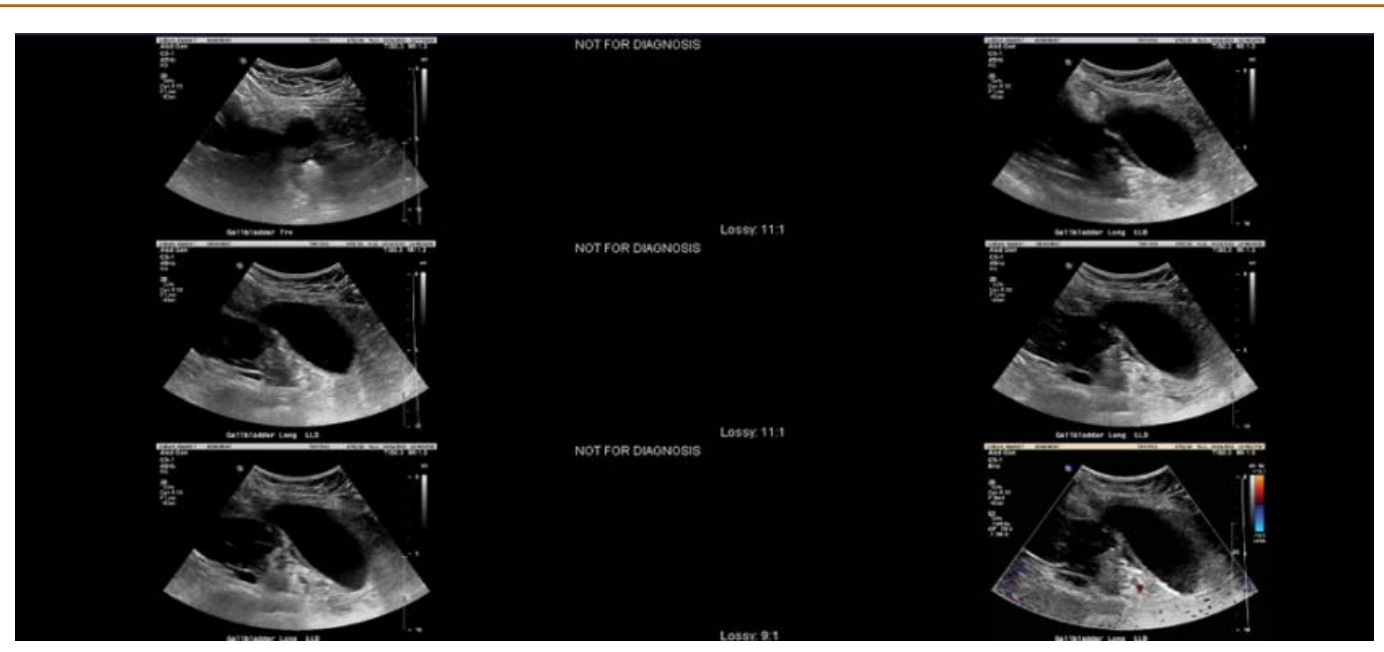

Figure 1 Gallbladder Ultrasound without any gallstones. Biliary sludge noted.

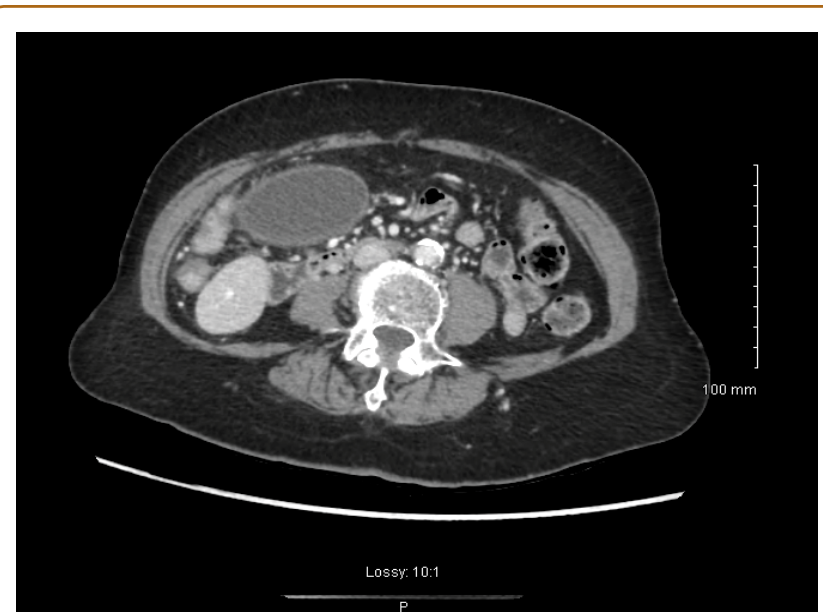

Figure 2 The gallbladder is moderatley distended with pericholcystic fluid, consistent with elements of inflammation.

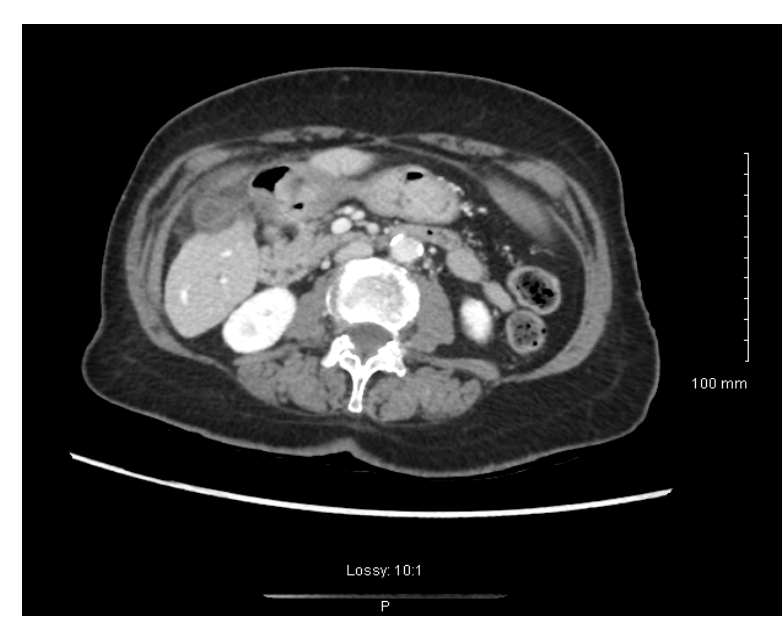

Figure 3 No visible gallstones per CT. No Bile duct dilation. Small, common hepatic and common bile duct.

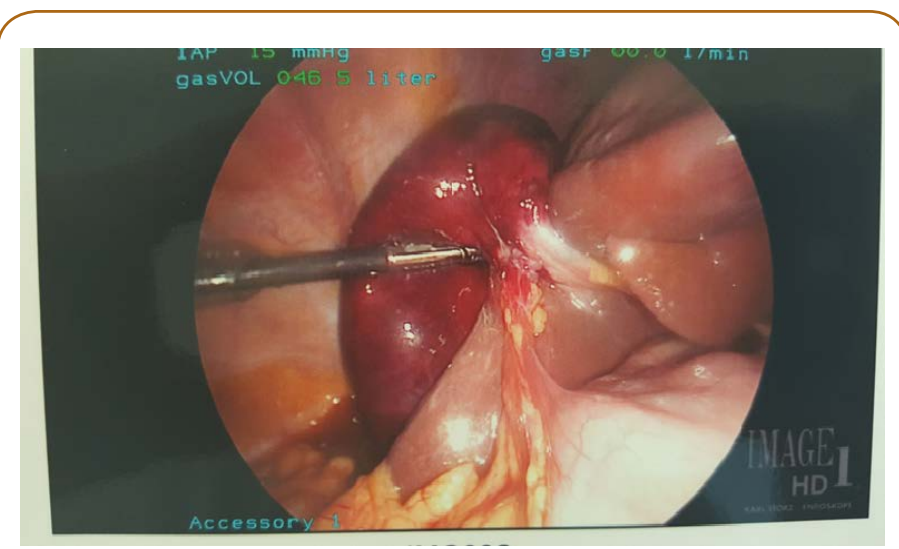

Figure 4 Hyperemic gallbladder with areas of necrosis.

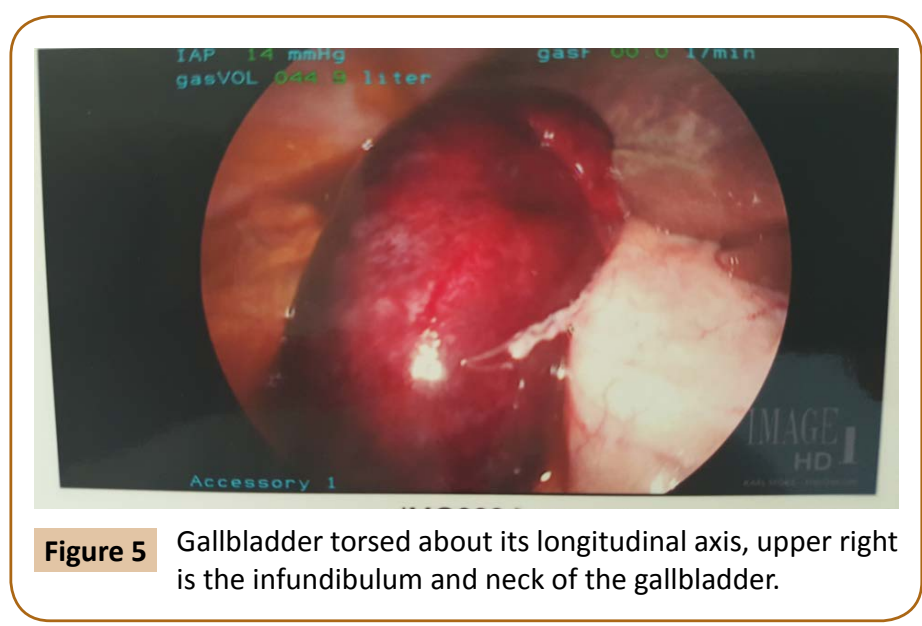

\section{Discussion}

Gallbladder volvulus is a rare condition that is more prominent in older, Caucasian females and the incidence appears to increase with age [2]. Our patient fit this description. 
The etiology of gallbladder volvulus is unknown but some underlying factors seem to be present. First the gallbladder is usually "floating" that is where the entire organ is in contact with the peritoneum and it is connected to the porta hepatis only by the cystic pedicle. A congenital anomaly may be present where an abnormally long mesentery can suspend the gallbladder away from the liver bed, thus increasing the chance for torsion. Likewise relaxation and atrophy of previously normal mesentery can cause visceroptosis [3].

But for the torsion to occur a triggering event has to occur. Liver atrophy, loss of visceral fat and elasticity, weight loss, atherosclerosis of the cystic artery and spinal deformities have all been theorized as possible triggering factors [4-7]. Interesting to note that our patient was very thin weighing just under 90 pounds, BMI 19.

Gallstones are unlikely to be the cause of torsion as they have been reported in only $20-33 \%$ of patients. One large study of 245 patients found stones in only $24.4 \% 8$ Preoperative diagnosis is difficult with fewer than a dozen cases found in the literature. Most diagnosis are made intraoperatively [8-11].

\section{Conclusion}

Gallbladder volvulus is a rare occurrence should be suspected in all patients presenting with signs and symptoms of acute cholecystitis, especially if they are elderly white woman. Delay in treatment can lead to necrosis, perforation and biliary peritonitis 


\section{References}

1 Wendel AV (1898) A case of floating gall-bladder and kidney complicated by cholelithiasis, with perforation of the gallbladder. Ann Surg 27:199-202.

2 Chung JC, Song OP, Kim HC (2010) Gallbladder torsion diagnosed by MDCT and MRCP. Abdom Imaging 35: 462-464.

3 Aibe H, Honda H, Kuroiwa T, Yoshimitsu K, Irie H, et al. (2002) Gallbladder torsion: Case report. Abdom Imaging. 27:51-53.

4 Janakan G, Ayantunde AA, Hoque $H$ (2008) Acute gallbladder torsion: An unexpected intraoperative finding. World J Emerg Surg 3: 9.

5 Pottorf BJ, Alfaro L, Hollis HW (2013) A clinician's guide to the diagnosis and management of gallbladder volvulus. Perm J 17: 80-83.

6 Tarhan OR, Barut I, Dinelek H (2006) Gallbladder volvulus: Review of the literature and report of a case. Turk J Gastroenterol 17: 209-211.
7 Ijaz S, Sritharan K, Russell N, Dar M, Bhatti T, et al. (2008) Torsion of the gallbladder: A case report. J Med Case Rep 2: 237.

8 Chou CT, Chen RC, Yang AD, Wu HK (2007) Gallbladder torsion: Preoperative diagnosis by MDCT. Abdom Imaging 32: 657-659.

9 Reddy PK, Muralidharan M, Venkatasubramanian R, Yuvaraja S (2005) Laparoscopic derotation and cholecystectomy for torsion gallbladder. JSLS 9: 238-240.

10 Gupta V, Singh V, Sewkani A, Purohit D, Varshney R, et al. (2009) Torsion of gall bladder, a rare entity: A case report and review article. Cases J 2:193.

11 Garciavilla PC, Alvarez JF, Uzqueda GV (2010)Diagnosis and laparoscopic approach to gallbladder torsion and cholelithiasis. JSLS 14:147-151.

12 Koyanagi T, Sato K (2012) Complete gallbladder torsion diagnosed with sequential computed tomography scans: A case report. J Med Case Rep.6:289. 